\title{
Comparative Study of ZnO Thin Films Prepared by Different Sol-Gel Route
}

\author{
F.E. Ghodsi* And H. Absalan \\ Department of Physics, Faculty of Science, University of Guilan \\ Namjoo Ave., P.O. Box: 41335-1914, Rasht, Iran \\ (Received April 17, 2010; in final form June 14, 2010)
}

\begin{abstract}
The $\mathrm{ZnO}$ thin films were prepared from zinc acetate dihydrate as main precursor by using sol-gel method and deposited by drainage and dip coating technique. Four different routes and coating techniques were used for the preparation of samples. The morphology, optical, and structural properties of the sol-gel made $\mathrm{ZnO}$ thin films were studied with respect to the preparation of sol-gel route, drainage and dip coating technique. The microstructure of the $\mathrm{ZnO}$ thin films and the powders were analyzed by X-ray diffraction. The ZnO thin films prepared in this study were amorphous while its powders were polycrystalline with various diffraction peaks in the X-ray diffraction patterns. The morphology of the film was examined by using scanning electron microscopy. The surface morphology of the $\mathrm{ZnO}$ thin films strongly depends on preparation route and deposition technique. The optical characteristics of the samples were obtained by using UV-Visible spectrophotometer at $200-900 \mathrm{~nm}$ wavelength. The optical constants (refractive index, extinction coefficient etc.) of the $\mathrm{ZnO}$ thin films depend on preparation conditions. The photoluminescence spectra of the $\mathrm{ZnO}$ films show the band-edge and sub-band transitions.
\end{abstract}

PACS numbers: 78.20.Ci, 78.55.Hx, 78.66.Bz, 81.20.Fw

\section{Introduction}

Thin films of zinc oxide $(\mathrm{ZnO})$ have attracted great attention for their applications in semiconductor devices, acoustic wave and acoustic-optical devices, photoconductors and optical waveguide devices because of their low resistivity, piezoelectric properties, high transparency in the visible range, and high light trapping characteristics [1-3]. In addition, $\mathrm{ZnO}$ thin films have good electrical and optical properties and are of lower material cost in comparison to the ITO films $[4,5]$. Several deposition methods such as sputtering [6], molecular beam epitaxy [7], vapor-phase deposition [8], thermal evaporation [9], reactive evaporation [10], chemical vapor deposition [11], spray pyrolysis [12], and sol-gel process [13], have been used for the preparation of $\mathrm{ZnO}$ thin films. The sol-gel methods are widely used for $\mathrm{ZnO}$ thin films fabrication due to several advantages in comparison with other deposition methods, e.g. its ability to prepare high quality thin films in large scale, its excellent control of stoichiometry, simplicity, safety, low cost of the apparatus and raw materials.

The optical and structural properties of sol-gel derived $\mathrm{ZnO}$ thin films depend critically on several phys-

* corresponding author; e-mail: feghodsi@guilan.ac.ir ical and chemical parameters such as deposition technique, drying process, annealing temperature, $\mathrm{pH}$ of solution, concentration of solution etc. In the present work, we compare the optical and morphological properties of the $\mathrm{ZnO}$ thin films prepared by using four different sol-gel routes. A systematic comparison has been done between two samples (S1 and S3) with similar sol preparation routes and different coating (dip and drainage) techniques. Other systematic comparison has been done between three samples (S2, S3, and S4) with different sol preparation routes and similar coating techniques. We did not get a continuous thin film starting from sols prepared by route 2 and 4 and using drainage coating technique due to the restriction of this technique. In the drainage coating technique, the sol removes from the bottom of the container and flows to another container. This condition aged the sol rapidly and did not allow the repetition of the process with the same viscosity.

\section{Experimental}

$\mathrm{ZnO}$ thin films were prepared using the sol-gel method and deposited onto glass substrates (Slides-Cat. No. 7102 ) by the drainage and dip coating techniques. Four different routes were used for the deposition of $\mathrm{ZnO}$ thin films (Fig. 1). Zinc acetate dihydrate (ZAD) were used as main precursor for all samples. For the preparation 


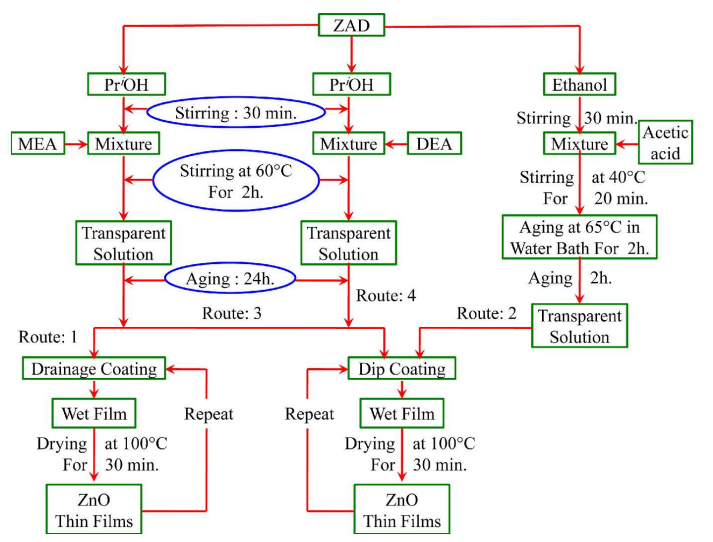

Fig. 1. Flow chart for the preparation of the $\mathrm{ZnO}$ thin films by using different sol-gel routes and coating techniques.

of the first sample (S1), the sol was prepared by dissolving $4.9 \mathrm{~g}$ of zinc acetate dihydrate $\left[\mathrm{Zn}\left(\mathrm{CH}_{3} \mathrm{CO}_{2}\right)_{2} \cdot 2 \mathrm{H}_{2} \mathrm{O}\right]$ (Merck, 99.98\%) in $150 \mathrm{ml}$ of dehydrated isopropyl alcohol, $\left(\mathrm{pr}^{i} \mathrm{OH}\right)(\mathrm{Merck},>99.9 \%)$. The solution was stirred thoroughly on a magnetic stirrer for $30 \mathrm{~min}$. A milky solution was obtained. Then, $8 \mathrm{ml}$ of monoethanolamine, MEA $\left[\mathrm{NH}_{2} \mathrm{C}_{2} \mathrm{H}_{4} \mathrm{OH}\right]$ (Merck, $+99 \%$ ) was added to the solution as stabilizer drop by drop until it became transparent. The solution was mixed by a magnetic stirrer at
$60{ }^{\circ} \mathrm{C}$ for about $2 \mathrm{~h}$. To yield a stable, clear and homogeneous sol, it was kept at room temperature for about $24 \mathrm{~h}$. Finally, the sol was deposited by the drainage coating technique. For the preparation of the second sample (S2), $4.4 \mathrm{~g}$ of zinc acetate dihydrate was dissolved into $100 \mathrm{ml}$ of anhydrous ethanol, $\mathrm{C}_{2} \mathrm{H}_{5} \mathrm{OH}$ (Merck, > 99.9\%) and stirred on a magnetic stirrer for $30 \mathrm{~min}$. Then, a small amount $(0.4 \mathrm{ml})$ of glacial acetic acid $\left[\mathrm{CH}_{3} \mathrm{COOH}\right]$ (Merck, $>99.9 \%$ ) was added to the mixture and stirred at $40^{\circ} \mathrm{C}$ for $20 \mathrm{~min}$. The obtained transparent solution was aged in a water bath at $65^{\circ} \mathrm{C}$ for $2 \mathrm{~h}$. Further $2 \mathrm{~h}$ of aging at room temperature was applied to obtain transparent and homogenous solution. The dip coating technique was used for the deposition of the second sample (S2). For the preparation of the third sample (S3), the first synthesis route was used for the preparation of the sol but it was deposited by the dip coating technique. For the preparation of the fourth sample (S4), the first synthesis route was used for the preparation of the sol with $3.3 \mathrm{~g}$ zinc acetate dihydrate and $70 \mathrm{ml}$ of dehydrated isopropyl alcohol, $\left(\mathrm{pr}^{i} \mathrm{OH}\right)$, but instead of $8 \mathrm{ml}$ of monoethanolamine, $4 \mathrm{ml}$ of diethanolamine, DEA $\left[\mathrm{HN}\left(\mathrm{C}_{2} \mathrm{H}_{4} \mathrm{OH}\right)_{2}\right]($ Merck, $+99 \%)$ was used as stabilizer. Then, the dip coating technique was used for the preparation of sample four (S4). Due to low concentration of MEA, DEA, and acetic acid used for the preparation of the sols, a slight change was measured for the $\mathrm{pH}$ of sols (Table).

TABLE

The values of $\mathrm{pH}$, refractive index, $n$, and extinction coefficient, $k$, at $550 \mathrm{~nm}$ wavelength, thickness, $d$, and band gap energy, $E_{\mathrm{g}}$ of the $\mathrm{ZnO}$ thin films prepared at different preparation routes and coating techniques.

\begin{tabular}{c|c|c|c|c|c|c|c}
\hline \hline Sample & Technique & $\mathrm{pH}$ & $n$ & $k$ & $d[\mathrm{~nm}]$ & $E_{\mathrm{g}}[\mathrm{eV}]$ & Morphology \\
\hline S1 & drainage & 7.1 & 1.582 & 0.014 & 348 & 3.28 & porous \\
S2 & $\operatorname{dip}$ & 6.5 & 1.591 & 0.015 & 312 & 3.11 & rough \\
S3 & $\operatorname{dip}$ & 7.1 & 1.608 & 0.022 & 376 & 3.08 & microcrack \\
S4 & $\operatorname{dip}$ & 6.8 & 1.623 & 0.013 & 358 & 3.27 & smooth
\end{tabular}

Glass substrates were cleaned with water and detergent. Then, they were cleaned with deionized water in an ultrasonic cleaner and washed with a mixture of acetone and alcohol. Drainage and dip coating was applied thereafter into solution by a deposition rate of $8 \mathrm{~cm} / \mathrm{min}$. Then, the coated films were dried at $100{ }^{\circ} \mathrm{C}$ in air for $30 \mathrm{~min}$. The process was repeated nine times to prepare films with desired thickness. Finally, the $\mathrm{ZnO}$ thin films were heat treated at $400{ }^{\circ} \mathrm{C}$ in a furnace.

The $\mathrm{pH}$ of solutions was measured by a $\mathrm{pH}$ meter model Jenway-3505 G. Britan. The structural characterizations of the $\mathrm{ZnO}$ powder and thin films were performed using a PHILIPS PW-1840 X-ray diffractometer with $\mathrm{Cu} K_{\alpha}$ radiation from 5 to $60^{\circ} 2 \theta$ in steps of $0.05^{\circ}$.
The surface morphology of the $\mathrm{ZnO}$ thin films was investigated using a PHILIPS XL30 scanning electron microscope (SEM) equipped with an energy dispersive X-ray (EDX) analyzer operated at $20 \mathrm{kV}$ acceleration voltage. To obtain the optical constants of the $\mathrm{ZnO}$ thin films, the optical transmittance measurements were carried out using a Varian Cary-100 UV-Visible spectrophotometer in the spectral range of $200-900 \mathrm{~nm}$ at normal incidence. Photoluminescent spectra were measured using a JASCO FP-6200, Japan spectrofluorometer with a slit width of $5 \mathrm{~nm}$. The excitation wavelength was set at $325 \mathrm{~nm}$. 


\section{Results and discussion}

$\mathrm{X}$-ray diffraction (XRD) analyses of $\mathrm{ZnO}$ thin films annealed at $400^{\circ} \mathrm{C}$, and powders annealed at 200 and $500^{\circ} \mathrm{C}$ are depicted in Fig. 2. One can see that the $\mathrm{ZnO}$ thin films exhibit amorphous structure and no peaks of any crystalline phase of $\mathrm{ZnO}$ are observed. Similar amorphous structure is obtained for all samples independent of preparation conditions. The XRD pattern of $\mathrm{ZnO}$ powders show diffraction peaks from various directions of $\mathrm{ZnO}$. The powders are mainly polycrystalline, and exhibit (100), (002), (101), (102), and (110) peaks. The relative intensity of the peaks increases with annealing temperature.

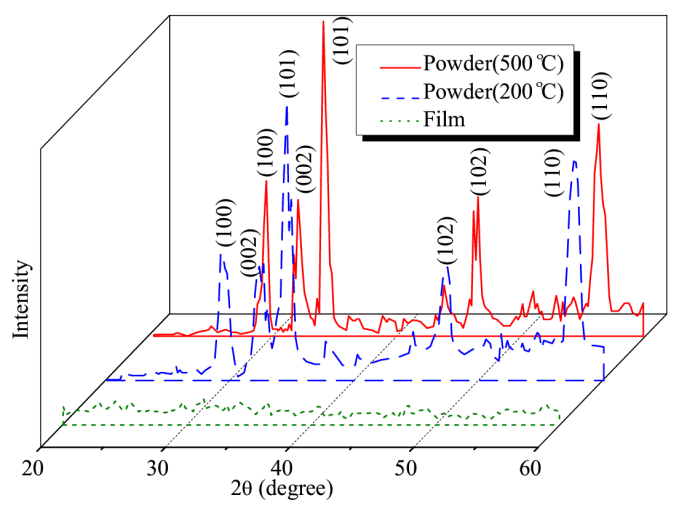

Fig. 2. XRD patterns of the $\mathrm{ZnO}$ thin films and their powders annealed at different temperatures.

The optical constants and thickness of $\mathrm{ZnO}$ thin films were determined by minimizing of generated transmission with respect to experimental data [14]. A satisfactory agreement between theoretical and experimental data for a sample is shown in Fig. 3. The calculated refractive index, $n$, and extinction coefficient, $k$, of the $\mathrm{ZnO}$ thin films are fitted to the Sellmeier relationship [14] given by

$$
n(\lambda)=\left(A_{n}+\frac{B_{n} \lambda^{2}}{\lambda^{2}-C_{n}^{2}}\right)^{-1 / 2}
$$

and

$$
k(\lambda)=\left[n(\lambda)\left(B_{1} \lambda\right)+\frac{B_{2}}{\lambda}+\frac{B_{3}}{\lambda^{3}}\right]^{-1},
$$

where $A_{n}, B_{n}, C_{n}, B_{1}, B_{2}$, and $B_{3}$ are the fitting parameters.

The refractive index of drainage coated $\mathrm{ZnO}$ thin film (S1) as a function of wavelength is given in Fig. 4. The refractive index decreases with the increase of wavelength according to the Sellmeier formula. Figure 5 represents the extinction coefficient of the $\mathrm{ZnO}$ thin film with respect to wavelength for the same sample 1 (S1). The extinction coefficient shows dispersion behavior according to the Sellmeier relationship of extinction coefficient.

The direct and indirect allowed optical transitions can be evaluated by fitting a straight line in strong absorption spectral region using the Tauc relationship [15]. Ac-

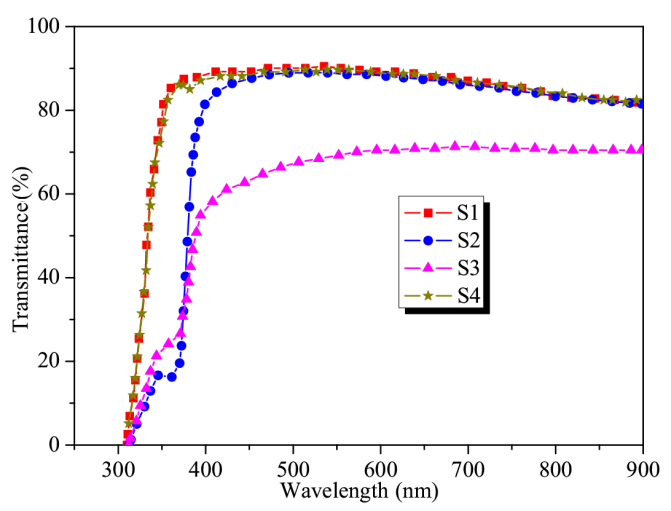

Fig. 3. UV-Vis spectra of sol-gel made $\mathrm{ZnO}$ thin films prepared by different routes and coating techniques.

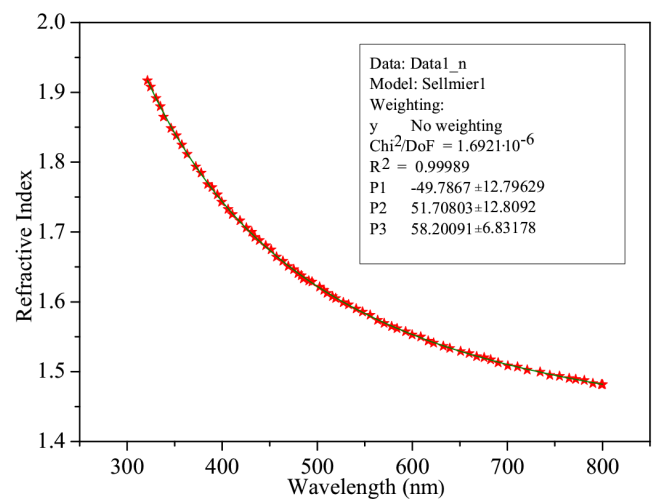

Fig. 4. Wavelength dependence of the refractive index of the $\mathrm{ZnO}$ thin films (S1).

cording to the Tauc law, the dependence of absorption coefficient on photon energy can be given by

$$
\alpha h \nu=\left(h \nu-E_{\mathrm{g}}\right)^{r}
$$

formula, where $h \nu$ and $E_{\mathrm{g}}$ are the photon energy and the optical band gap, respectively. For direct transition

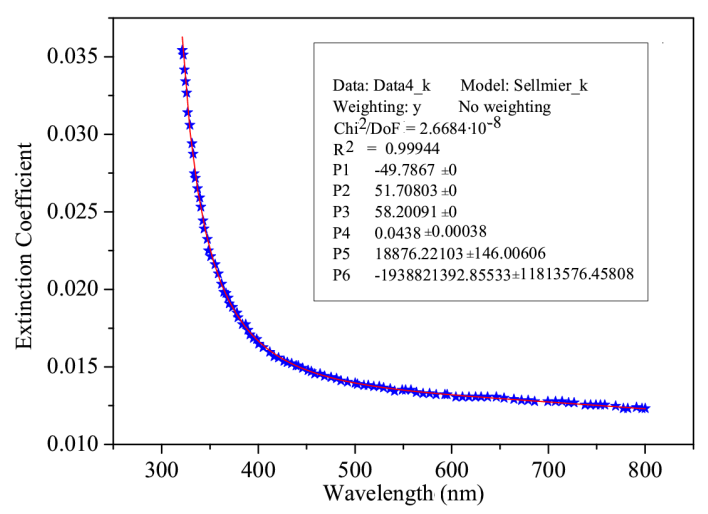

Fig. 5. Changes in the extinction coefficient with wavelength of the $\mathrm{ZnO}$ thin films (S1). 
$r$ equals $1 / 2$, and for indirect transition $r$ equals 2 . The energy band gap is evaluated by extrapolating the refractive index and absorption coefficient in strong absorption spectral region tail by crossing $(\alpha h \nu)^{1 / r}$ with $h \nu$ axis when $(\alpha h \nu)^{1 / r}$ varies dramatically. Plot of $(\alpha h \nu)^{1 / 2}$ versus $h \nu$ for the direct optical transitions of the $\mathrm{ZnO}$ thin film for the same sample 1 (S1) is given in Fig. 6 .

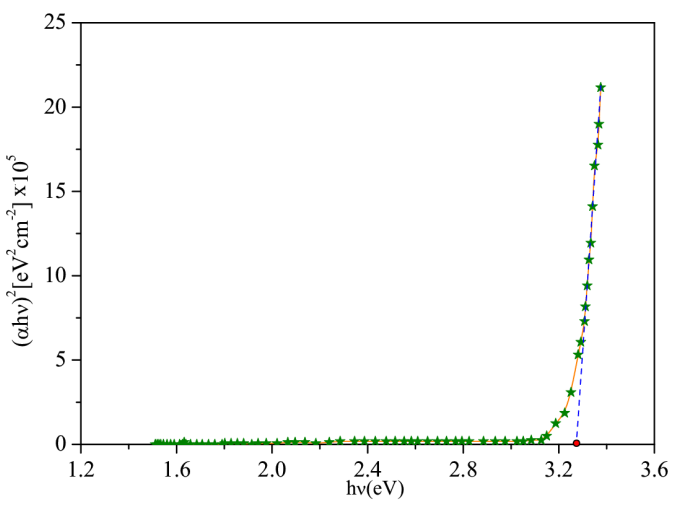

Fig. 6. Plot of $(\alpha h \nu)^{1 / 2}$ versus $h \nu$ for the direct optical transition of the $\mathrm{ZnO}$ thin films (S1).

The $\mathrm{pH}$ of the starting sol and calculated values of film refractive index at $550 \mathrm{~nm}$ wavelength, $n$, extinction coefficient at $550 \mathrm{~nm}$ wavelength, $k$, thickness of the films, $d$, and band gap energy, $E_{\mathrm{g}}$ are tabulated in Table. The variation of the optical constants with respect to preparation route can be explained as morphological and structural changes in the samples. The refractive index and extinction coefficient decrease with the increase of porosity as can be seen from SEM images (Figs. 7a-d). In addition, the roughness of the surface causes enhanced light scattering on the surface of the sample (S2) that increases the refractive index, consequently. On the other hand, the thickness of sample 3 (S3) is larger than that of the other samples, so the extinction coefficient of sample 3 is higher than the value of the other samples.

Figure 7 shows the micrographs of the surface topography of $\mathrm{ZnO}$ in thin films grown at different conditions. For sample 1 (S1), the surface shows a rough and porous structure. The porous structure is uncharacteristic for sample 2 (S2), however, its roughness is high. For sample 3 (S3), the rough and porous structure disappeared and a smoother surface with a few microcracks is obtained. A homogeneous and smooth surface without any crack is achieved for the sample 4 (S4).

Figure 8 illustrates the photoluminescence spectra of the $\mathrm{ZnO}$ thin films deposited at different conditions and recorded at room temperature. The PL spectra for the sol-gel derived $\mathrm{ZnO}$ thin films which are deposited at different conditions contained various emission features, which change their intensity and positions with the preparation conditions. The sample 1 (S1) shows two photoluminescence emission peaks. A sharp peak of sample 1 is localized at around $379 \mathrm{~nm}$ which corre-
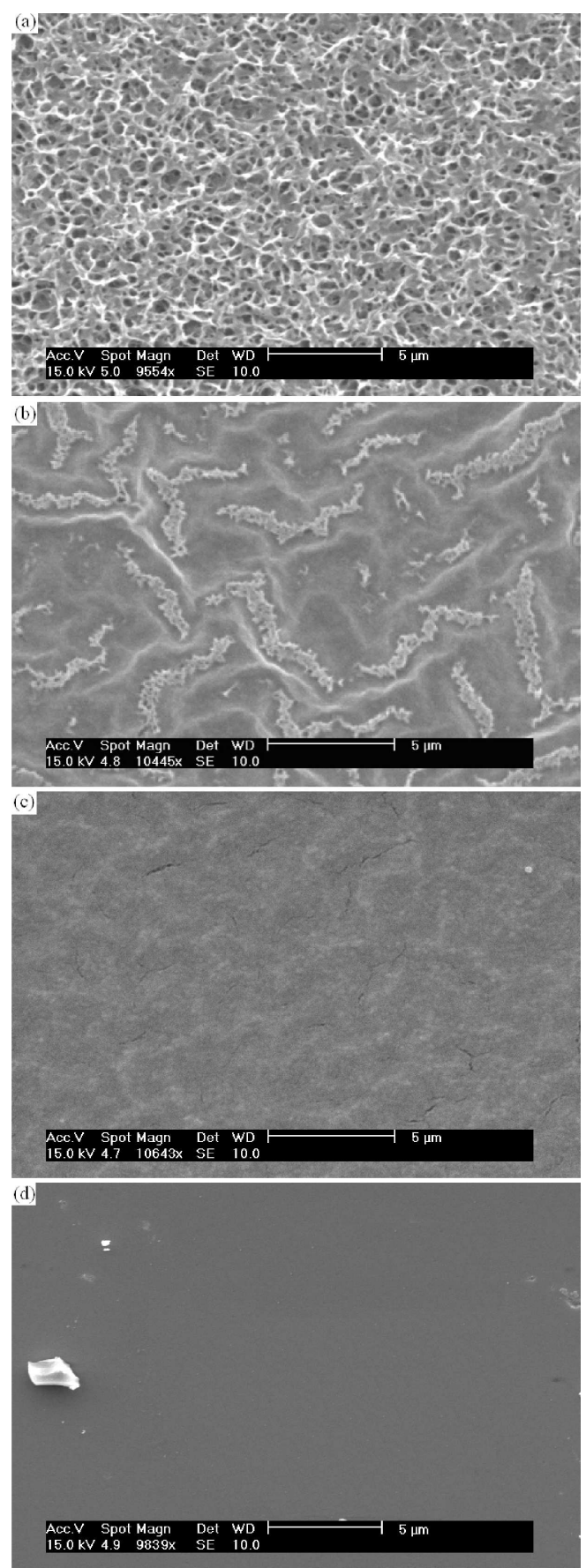

Fig. 7. Scanning electron microscopy (SEM) images of the $\mathrm{ZnO}$ thin films deposited at different conditions: (a) S1, (b) S2, (c) S3, and (d) S4.

sponds to the band-to-band transition. The second peak is a weak broad band in the visible region (bluish-green to yellow-green emission). The bluish-green to yellow-green emissions are attributed to deep level defects in $\mathrm{ZnO}$ thin films, such as doubly-ionized and single-ionized interstitial zinc vacancies and oxygen vacancies [16, 17]. In addition, the sharp intensity of the near-band-edge and broadening of the visible band is attributed to the 
porous structure of the films [18]. An excitonic emission at $388 \mathrm{~nm}$, a broad band to band transition peak at about $400 \mathrm{~nm}$, and a nearly broad band deep level peak at about $537 \mathrm{~nm}$ are observed for sample 2 (S2). It is proposed that the broadening of band-to-band transition peak is related to the antisite defects and the roughness of surface of the films. The UV emission peak at $375 \mathrm{~nm}$ for sample 3 (S3) may be due to excitonic recombination phonon process near the band-edge levels of $\mathrm{ZnO}$ [19]. The nearly broad band peak at about $404 \mathrm{~nm}$ is attributed to the band-to-band transition. Slight broadening of band-to-band transition peak might be related to the existence of microcrack on the surface of the films. A deep level peak at $537 \mathrm{~nm}$ (green emission) is attributed to zinc vacancies. Sample 4 (S4) shows an excitonic peak at $376 \mathrm{~nm}$, sharp band-to-band transition peak at $381 \mathrm{~nm}$ and relative weak peak at $517 \mathrm{~nm}$ (green emission) due to the deep level defects such as zinc vacancy.

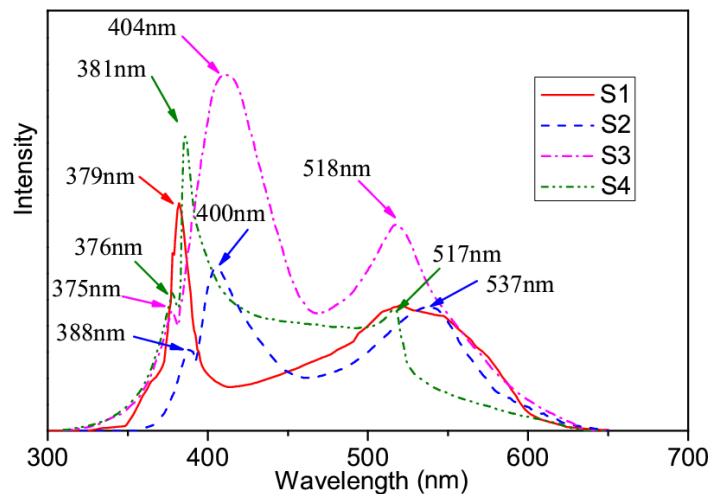

Fig. 8. Photoluminescence spectra of the sol-gel derived $\mathrm{ZnO}$ thin films prepared at different conditions.

Samples S1 and S3 were prepared using the same sol. Sample 1 (S1) was deposited by the drainage technique and sample 3 (S3) by the dip coating technique. During the drainage technique, the substrate has been placed into the container and the sol has been removed from the bottom of the container. In this case, there is no significant difference between the evaporation of solvent during removing of sol and later. However, in the dip coating technique, there is a considerable difference between the evaporation of solvent during withdrawing step and evaporation step. In the evaporation step, the solvent evaporates rapidly due to air flux around the sample. While for the drainage technique, there is a slow evaporation of the solvent. Therefore, the aggregation of the wet gel is slow for drainage technique while it is fast for the dip coating technique. Furthermore, MEA was also used as stabilizer in sol samples. Due to lower and weaker bonding of the MEA in the polymeric chain, the polymers break down during the evaporation. The pores of sample 1 have been formed due to good elasticity resulting from slow pre-evaporation. Contrarily, drying of sample 3 (S3) caused cracking of the sample due to fast pre-evaporation. On the other hand, the DEA has formed more bonding and stronger bonds in polymeric chain. Thus, the fast evaporation in the dip coating technique and drying of sample 4 (S4) causes breakdown of the polymers. Consequently, the surface of sample 4 (S4) is smooth. For the preparation of sample $2(\mathrm{~S} 2)$, the ethanol molecules have been used which are shorter than the isopropanol molecules. Therefore, the polymeric chains have not been formed longer and local aggregation formed on the surface of the films with more roughness. In addition, MEA and DEA act as a complexing agent, also retarding the $\mathrm{Zn}$ (II) condensation; however, the presence of the amine also increases the $\mathrm{pH}$, which should promote the formation of $\mathrm{ZnO}[20]$. On the other hand, the properties of the films are not considerably affected by the $\mathrm{pH}$ of the sol in the present work due to low change of $\mathrm{pH}$ (Table).

\section{Conclusion}

We found that porous $\mathrm{ZnO}$ thin films can be obtained using the drainage coating technique with the appropriate sol-gel route. The optical and morphological properties of the sol-gel derived $\mathrm{ZnO}$ thin films strongly depend on the preparation conditions. The morphology of the $\mathrm{ZnO}$ thin films were changed with variation of the route and coating technique. Rough surfaces were formed when ethanol and acetic acid were used as interphase and catalyst, respectively. A very smooth surface can be achieved by using DEA instead of MEA and applying the dip coating technique. In this study, the structure of the $\mathrm{ZnO}$ thin films was amorphous and was independent of the route and coating technique. The optical properties of the $\mathrm{ZnO}$ thin films strongly depended on the sol-gel routes and the coating techniques. The PL spectra reveal that the dip coated thin film using DEA as stabilizer for the sol exhibits better quality as the band edge transition peak is intense and the sub-band transition peak is suppressed. There is a good agreement between the optical and morphological properties of the samples prepared in this study.

\section{Acknowledgments}

The authors gratefully acknowledge Prof. Zanjanchi for using X-ray diffractometer and employers of Materials Department of AEOI-NRCAM, Karaj, for use of scanning electron microscope.

\section{References}

[1] W. Water, S. Yuan Chu, Mater. Lett. 55, 67 (2002).

[2] Y. Huang, M. Liu, S. Jiang, Y. Zeng, C. Li, S. Liu, D. Zhou, Microelectron. Eng. 66, 760 (2003).

[3] H. Sato, T. Mianini, Y. Tamura, S. Takata, T. Mouri, N. Ogawa, Thin Solid Films 246, 86 (1994).

[4] T.L. Chu, S.S. Chu, J. Electron. Mater. 19, 1003 (1990).

[5] H. Kobayashi, H. Mori, Y. Ishida, J. Appl. Phys. 77, 1301 (1995) 
[6] M.-S. Wu, W.-C. Shih, W.-H. Tsai, J. Phys. D, Appl. Phys. 31, 943 (1998).

[7] K. Nakamura, T. Shoji, K. Hee-Bog, Jpn. J. Appl. Phys. Part 2: Lett. 39, 534 (2000).

[8] A.K. Gyani, O.F.Z. Khan, P.O. Brien, D.S. Urch, Thin Solid Films 182, L1 (1989).

[9] J. Ma, F. Ji, H.-I. Ma, S.-Y. Li, J. Vac. Sci. Technol. A 13, 92 (1995).

[10] S. Nassem, M. Iqbal, K. Hussain, Sol. Energy Mater. 31, 155 (1993).

[11] T. Minami, H. Sonohara, S. Takata, H. Sato, Jpn. J. Appl. Phys., Part 2: Lett. 33, 743 (1994).

[12] F.D. Paraguay, W.L. Estrada, D.R.N. Acosta, E. Andrade, M. Miki-Yoshida, Thin Solid Films 350, 192 (1999).

[13] M.N. Kamalasanan, S. Chandra, Thin Solid Films 288, 112 (1996).
[14] D. Poelman, P. Frederic Smet, J. Phys. D, Appl. Phys. 36, 1850 (2003).

[15] J. Tauc, R. Grigorvici, Y. Yanca, Phys. Status Solidi 15, 627 (1966)

[16] S.A. Studenikin, N. Golego, M. Cocivera, J. Appl. Phys. 84, 4 (1998).

[17] K. Vanheusden, C.H. Seager, W.L. Warren, D.R. Tallant, J.A. Voigt, J. Appl. Phys. 68, 403 (1996).

[18] R.B. Wehrspohn, Ordered Porous Nanostructures and Applications, Springer Science+Business Media Inc., New York 2004, p. 59.

[19] S.A. Studenikin, N. Cocivera, H. Pascher, J. Lumin. 91, 223 (2000).

[20] L. Znaidi, G.J.A.A. Soler Illia, S. Benyahia, C. Sanchez, A.V. Kanaev, Thin Solid Films 428, 257 (2003). 